\title{
WEB BASED SMART IRRIGATION SYSTEM USING RASPBERRY PI
}

\author{
Dr. Dhiraj Sunehra \\ Department of Electronics \& Communication Engineering \\ Faculty of Engineering \& Technology \\ Jawaharlal Nehru Technological University Hyderabad, India
}

\begin{abstract}
The major population of India mainly depends upon Agriculture. Nowadays the ground water levels are also decreased due to global warming and uncertain rain fall. The conventional irrigation techniques have some problems like farmer should visit the field regularly even at night, then he may face some hazards like snake bite, electric shock and etc. In this paper a web based smart irrigation system using Raspberry Pi is implemented. The proposed system checks the temperature and moisture content present in the soil. The motor is also automatically controlled $O N$ and OFF, when the 3-phase supply is present in the field and also with the flow of water. The acquired temperature and moisture content of the soil are sent to Raspberry Pi using nRF24L01 transceiver. Raspberry Pi posts the received values on the webpage. When we enter the acquired parameter values in the soil test blogs, the webpage shows the suggestions of pesticides and crops that need to be taken by the farmer to increase the yield. The system can reduce the water consumption and wastage of water.
\end{abstract}

Keywords: Arduino, Raspberry Pi, Smart Irrigation, HTML, PHP

Cite this Article: Dr. Dhiraj Sunehra, Web Based Smart Irrigation System Using Raspberry PI, International Journal of Advanced Research in Engineering and Technology, 10 (2), 2019, pp 55-64.

http://iaeme.com/Home/issue/IJARET?Volume $=10 \&$ Issue $=2$

\section{INTRODUCTION}

Agriculture is the primary sector and backbone to the economy of India. Earlier the crop yielding was very high because the ground water levels were high. In the present day, to reduce the water consumption and increasing in the yield is a big challenge. Watering to the field is called irrigation. Watering to the soil is mainly depend upon soil moisture and temperature sensor values, if moisture content in the soil is less than the threshold, then it indicates watering is required to the field. In the literature, few irrigation management systems are reported, which have some limitations like, watering is done to the field without analysing the soil parameters, this causes non uniform water to the field, so it results in wastage of water and decrease in the yield. Sometimes human intervention is also required. To overcome them, the farmer needs an automatic irrigation system with advanced features like measuring the soil parameters (soil moisture, soil temperature and humidity sensors, etc). For that we propose a web based smart 
irrigation system using Raspberry Pi. The web based smart irrigation system means; farmer can monitor the sensor values and field status on the webpage. From the webpage farmer can know the water pump status and water level in the well. We can solve those problems by using a web based smart irrigation system. So the water is uniformly distributed to the field and helps to increasing in the yield.

\section{LITERATURE REVIEW}

Tanmay et al have implemented an Internet of Things (IoT) and WSN based crop security system which can detect rodents and insects, etc. in the field or storage godowns and intimate to the farmer in real time [1]. Satya et al have proposed a water irrigation system that controls the flow of water to the crops depending on the water level and the soil moisture. Also, the farmer receives a SMS notification about the amount of time that water is flown to the crops [2]. Usha Rani and Kamalesh designed a ZigBee and web based automatic irrigation system to monitor the soil moisture and motor status. An SMS is sent to the farmer about motor status [3]. Ghosh et al used cloud computing platform, a microcontroller and an isolated server to store sensor outputs and accordingly turn on or off drip irrigation system [4]. Namala et al implemented an intelligent and smart irrigation system for watering of flowering plants [5].

\section{HARDWARE DESCRIPTION}

\subsection{Block Diagram}

Figure 1 shows the block diagram of the transmitter section and Figure 2 shows the block diagram of the receiver section of Web based smart irrigation system using Raspberry Pi. Arduino receives the temperature, humidity and soil moisture parameters measured by the sensors and send them to Raspberry Pi through nRF24L01 module at transmitter section. Raspberry Pi receives those values and posts them on to the webpage at the receiver section.

\subsection{Raspberry Pi Model B+ Board}

Raspberry pi is a minicomputer, which is a credit card sized board. It is based on BCM2835 (BCM-Broadcom) system on chip (SoC). Its features include 512 MB of SDRAM, 40 GPIO pins, one Ethernet port, 4 USB ports, HDMI port Audio jack. It has a $700 \mathrm{MHz}$ ARM1176JZFS application processor (Figure 3). Serial receive $(\mathrm{Rx})$ and transmit $(\mathrm{Tx})$ pins are used for serial communication [6].

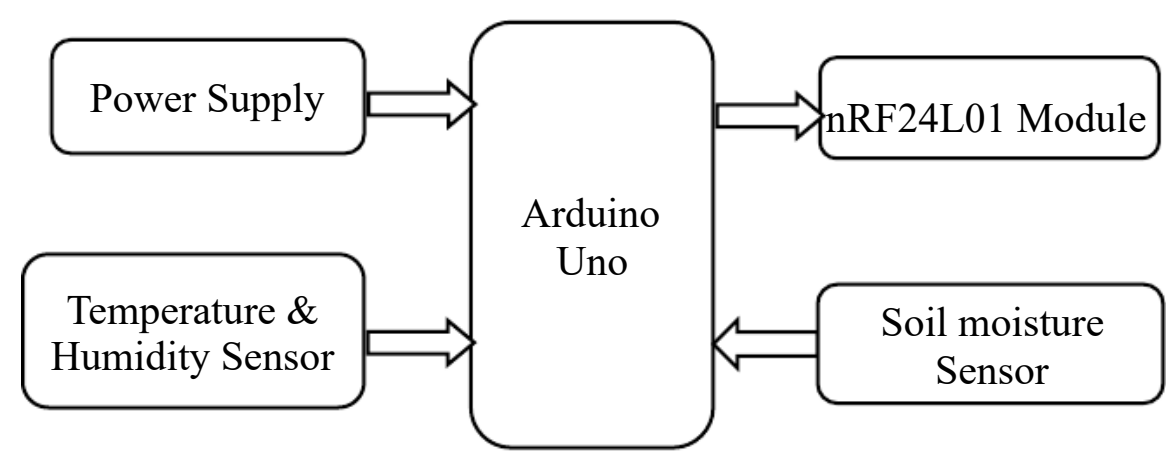

Figure 1 Block Diagram of Transmitter Section 


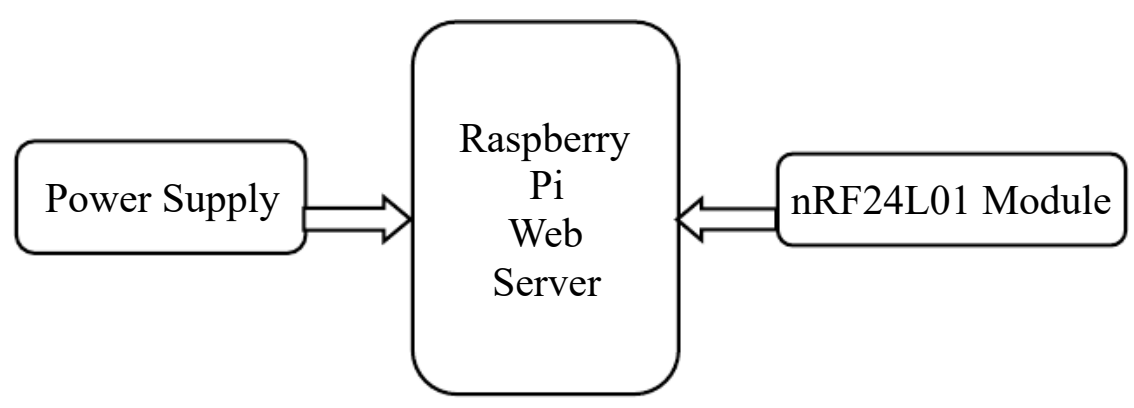

Figure 2 Block Diagram of Receiver Section

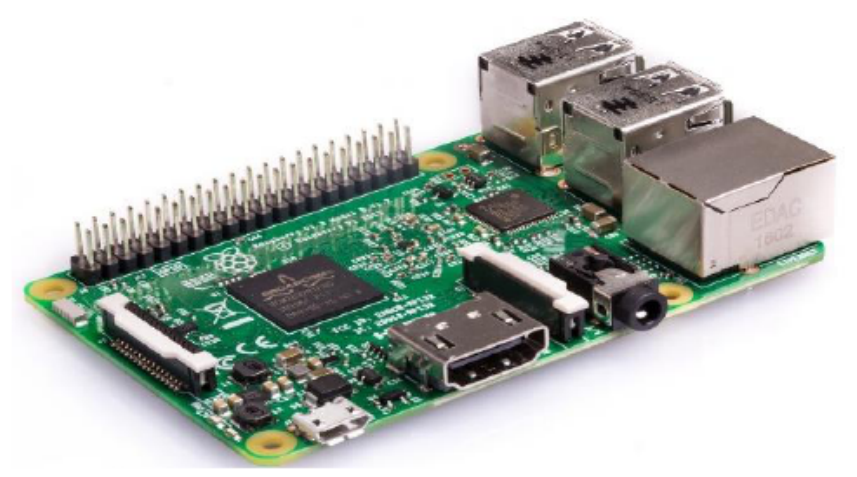

Figure 3 Raspberry Pi Model B+ Board

\subsection{Arduino Uno Board}

Arduino Uno board uses an ATmega328P microcontroller. It is an open source, platform independent and easy to use hardware and software [7]. ATmega328P microcontroller has a 28 pin configuration, in that 14 pins are used as digital pins and 6 pins used as analog pins (Figure 4). It has a $16 \mathrm{MHz}$ resonator, a USB connection, power jack and reset button. It has $2 \mathrm{~KB}$ of SRAM, $32 \mathrm{~KB}$ of on chip flash memory and $1 \mathrm{~KB}$ of EEPROM.

\section{4. nRF24L01 Wireless Transceiver}

Figure 5 shows the nRF24L01 $2.4 \mathrm{GHz}$ wireless transceiver [8]. It can send at up to $2 \mathrm{Mbps}$ data rate. We are using the nRF24L01 transceiver pair to connect Arduino and Raspberry Pi. It can handle the sensed data simultaneously from multiple nodes as it has collision detection mechanism. It needs a power supply of 1.9-3.6 V.

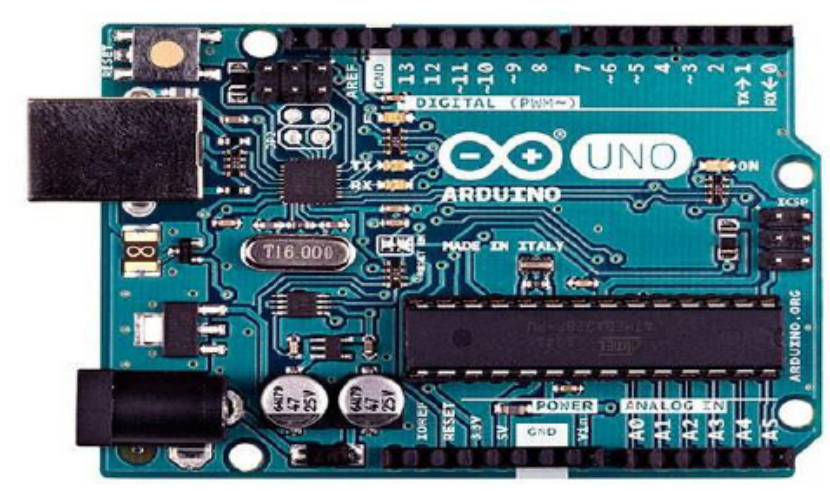

Figure 4 Arduino Uno Board 


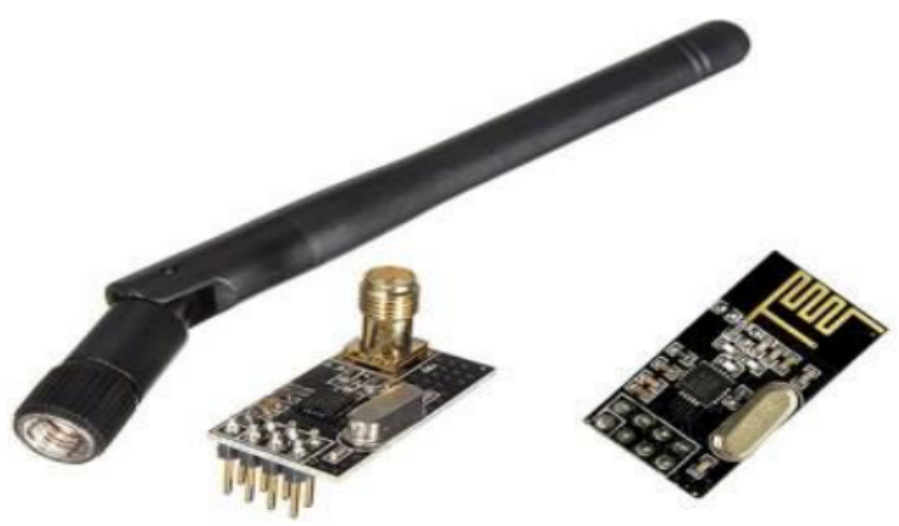

Figure 5 nRF24L01 Wireless Transceiver

\subsection{Temperature and Humidity Sensor}

DHT11 sensor is used as a weather sensor to read the temperature and humidity (Figure 6). It includes a resistive type component for measurement of humidity, and negative temperature coefficient type component for measurement of temperature [9]. The sensor also has an inbuilt 8-bit microcontroller. DHT11 sensor is having four pins, viz. Vcc, GND, Data (output), and last pin has no connection (NC).

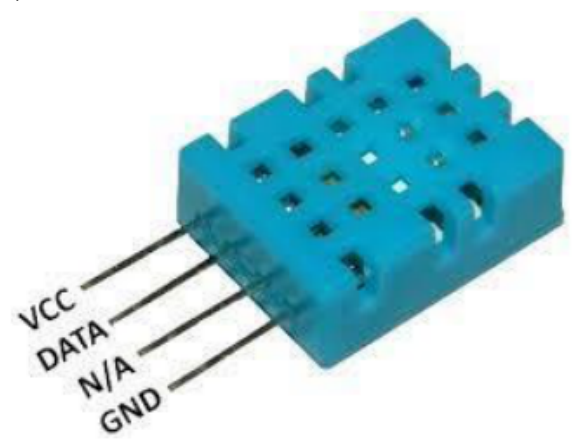

Figure 6 DHT11 Sensor

\subsection{Soil Moisture Sensor}

The soil moisture sensor contains two probes and one comparator circuit. This sensor provides the moisture content present in the soil. The comparator compares the soil moisture level with the set threshold level. When the soil is dry, the moisture becomes less than the threshold, and the sensor output becomes high and vice versa. It can be used to water the field appropriately and decreases wastage of water.

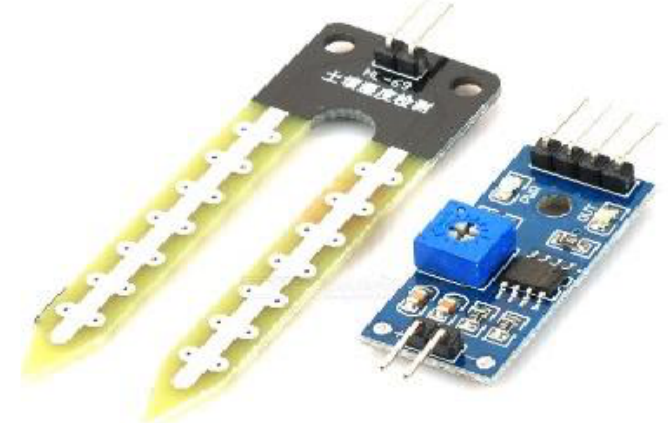

Figure 7 Soil Moisture Sensor 


\section{SOFTWARE TOOLS}

ExtraPuTTY is a software tool used to access Raspberry Pi. PuTTY is an open source terminal emulator. It can support various network protocols such as SCP, Telnet, rlogin and raw socket connection [10].

Arduino Integrated Development Environment (IDE) is used to write the code and upload it to Arduino board. It is an open source software which can support on various platforms like MAC OS X, Windows and Linux. The written code file should be saved with the extension of ino.

Python language is a high level script language [11]. Python is portable and it supports on UNIX, Linux and Windows operating system (OS) platforms. Python language fully supports the Raspberry Pi. The written program files are saved with the extension of .py.

HTML stands for Hypertext Markup Language and is used to create webpages [12]. HTML is a tag based language. PHP is a server side scripting language used to create dynamic web pages. It can perform system functions like read/write system files, etc.

\section{SCHEMATIC DIAGRAM AND FLOWCHART}

Figure 8 shows schematic diagram of the web based smart irrigation system, in which nRF24L01 module is connected to the digital pins of ATmega328P microcontroller in the transmitter section. In this, nRF24L01 module is supplied with $5 \mathrm{~V}$ and grounded from the microcontroller board. The temperature and humidity sensor (DHT11) is connected to the digital pin 5 of microcontroller. The soil moisture sensor output is connected to analog pin A0. L293D motor driver IC is connected to microcontroller and DC motor is connected to its output. In water level indicator, one wire is always connected to reference pin and it is always dip into the well. The other wire is connected to upper level of the well for indicating water level. In the Receiver section, the nRF24L01 module is interfaced with the Raspberry Pi.

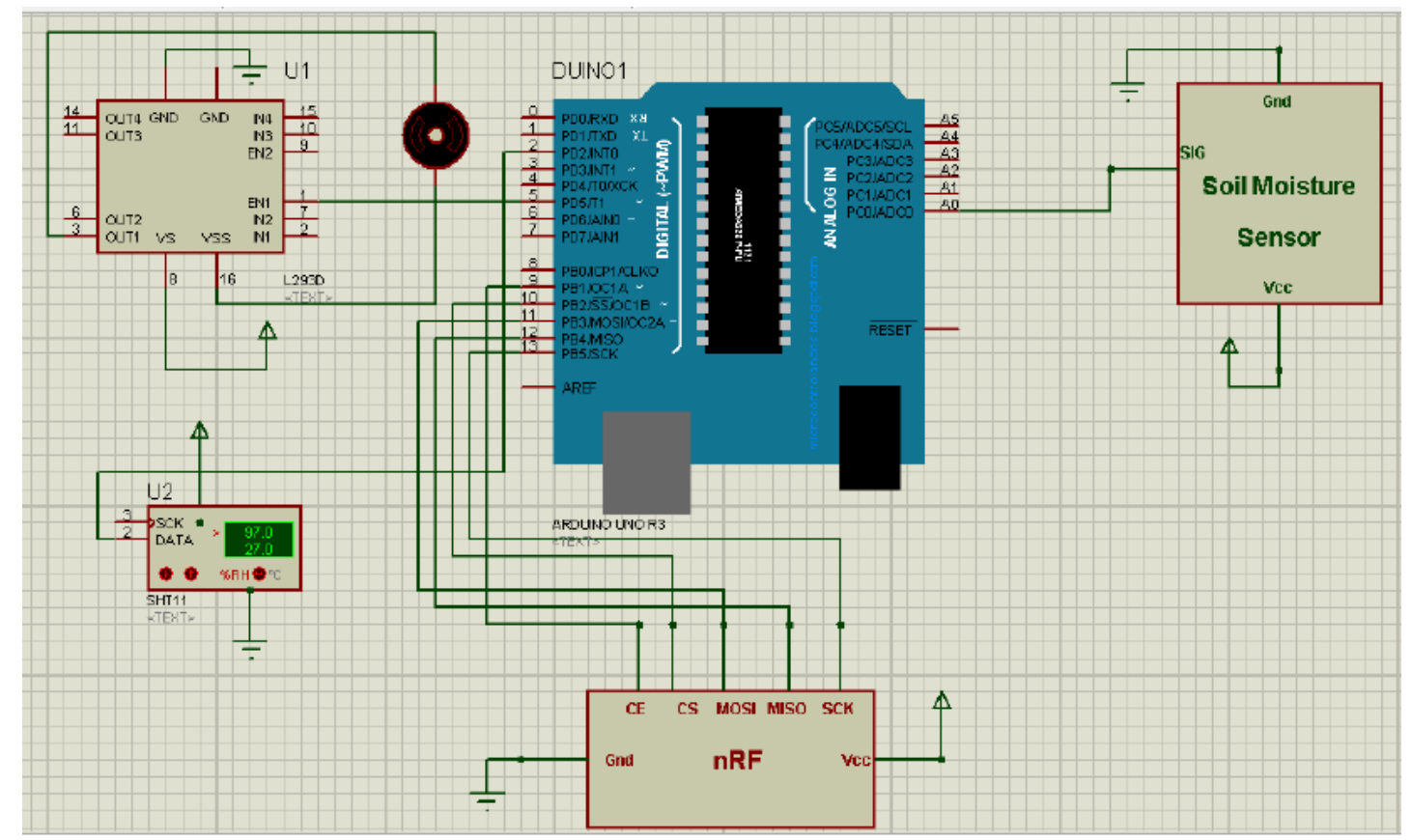

Figure 8 Schematic Diagram

Figure 9 shows software flowchart of smart irrigation system. First Arduino checks for the power supply. If the power supply is not present, no action will be done. If the power supply is present in the field then it checks for the soil moisture content of the field. If the soil moisture 
value is below 600 , it is denoted as the soil is wet, so there is no need to supply water. If the soil moisture value is greater than 600, it indicates that the soil is dry. Then Arduino checks for the water level in the well. If the water is not present in the well, then motor will be in OFF state. If the water is present in the well, then Arduino will turn ON the motor.

\section{EXPERIMENTAL SETUP AND RESULTS}

The complete experimental setup of the transmitter and receiver sections is shown in Figure 10 and Figure 11 respectively. The power supply of the microcontrollers is turned on. After turning on, the soil moisture sensor will sense the soil moisture parameter and feeds the value to the Arduino. The temperature and humidity sensor collects the temperature and humidity values and sends them to the Arduino. The Arduino microcontroller then sends this information to the receiver section through nRF24L01 module. The Raspberry Pi microcontroller in the receiver section displays the result on the webpage.

Whenever AC supply is present in the field, it will automatically turn ON the motor. At that time, it checks the two conditions. If the soil moisture content is greater than 600, it will turn ON the motor. At this time, it also checks for water level in well. Otherwise, it will turn OFF the motor.

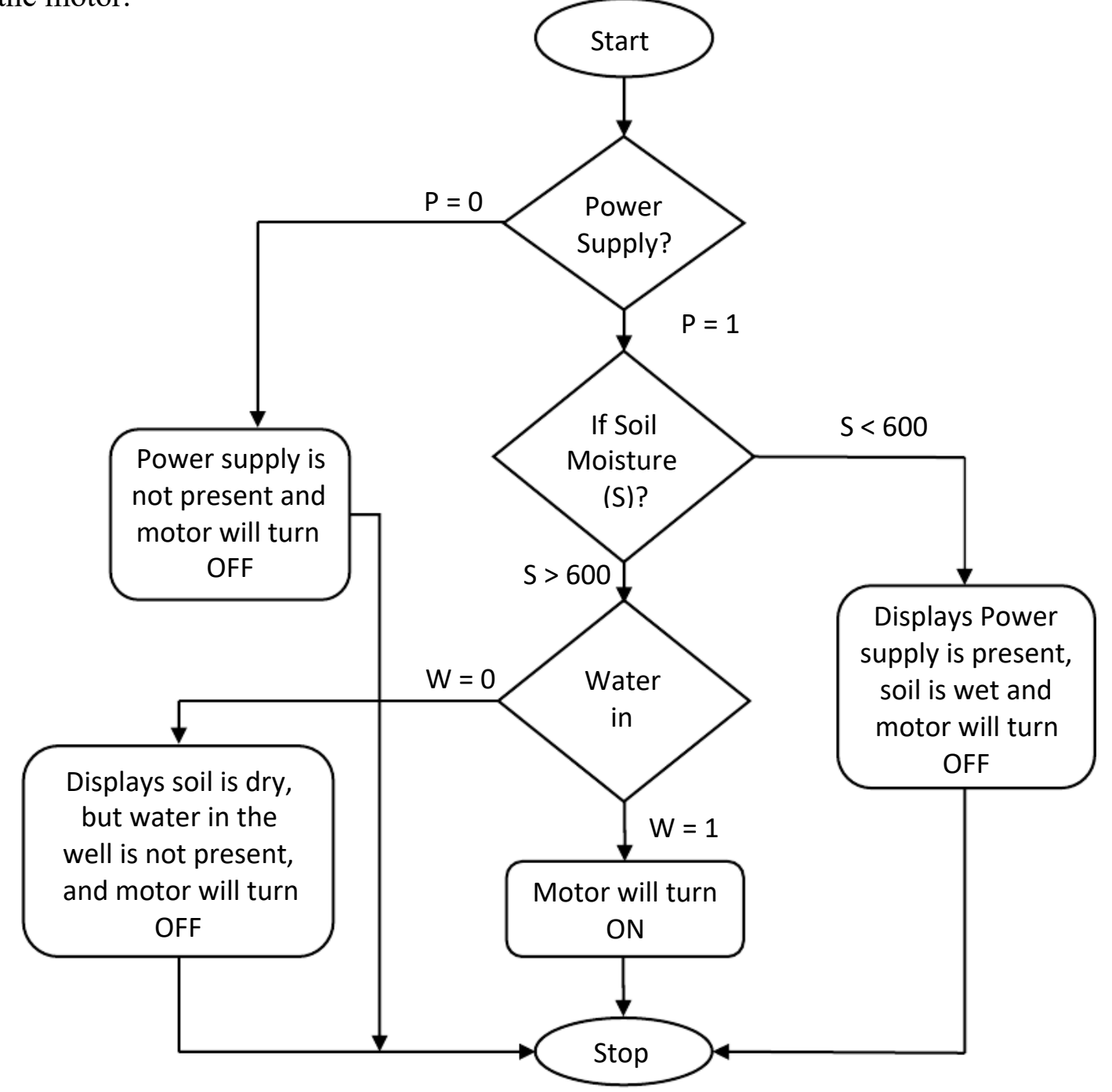

Figure 9 Flowchart of the sequence of events that occur in Smart Irrigation System

Figure 12 shows the results on Arduino IDE serial monitor. In the first sample, the temperature is displayed as $37^{\circ} \mathrm{C}$, humidity is $21 \%$, soil moisture ' 1004 '. This value indicates 
that soil is dry. The water level indication ' 1 ' means there in no sufficient water in the well and status of power ' 1 'indicates AC Power is available in the field and status of motor is turned OFF.

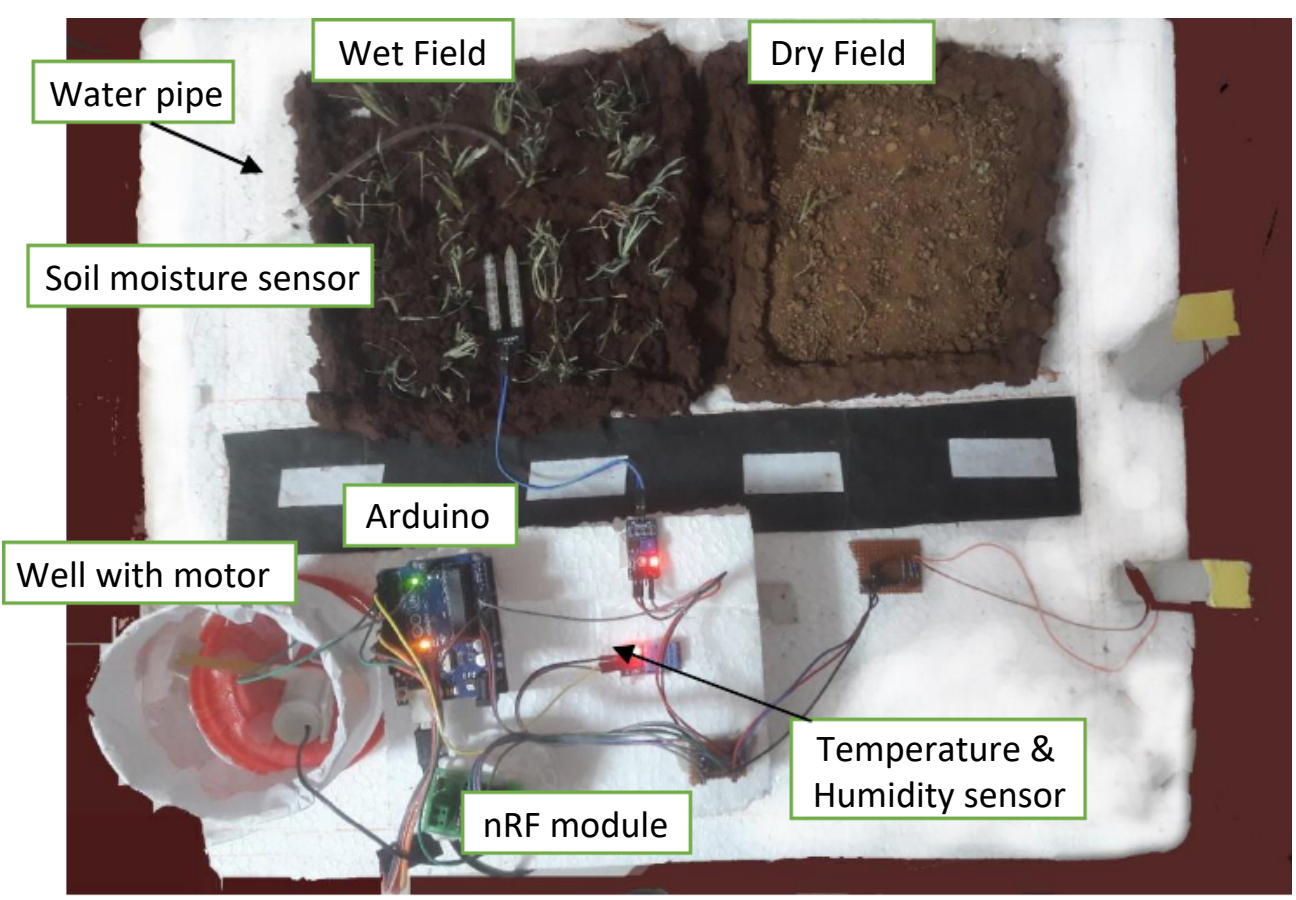

Figure 10 Experimental Setup of Transmitter section of Smart Irrigation System

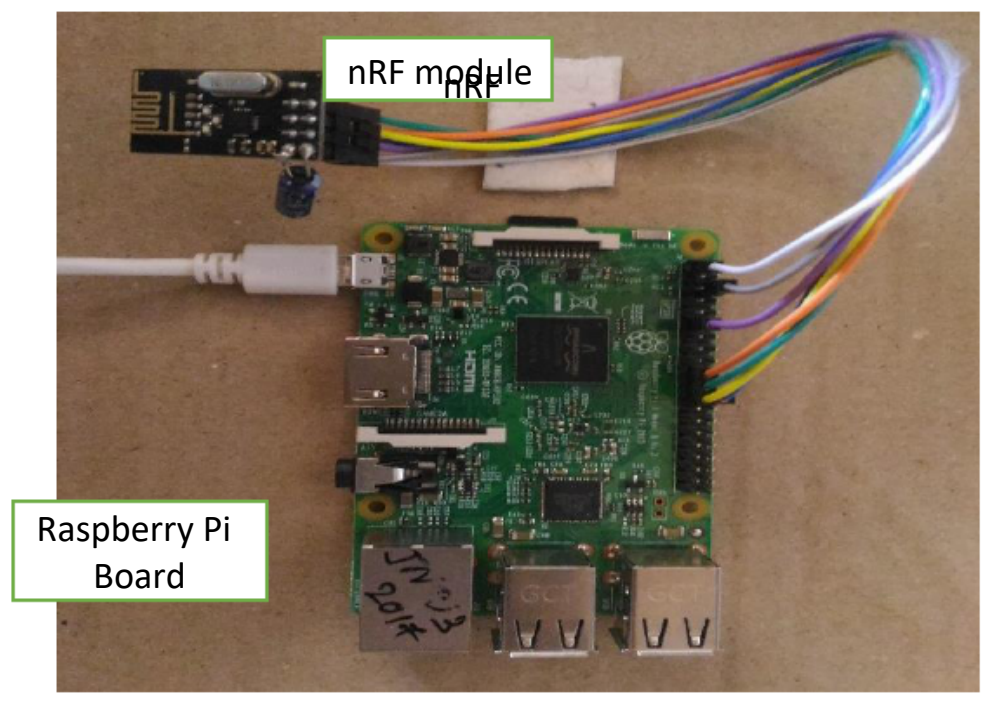

Figure 11 Experimental Setup of Receiver section of Smart Irrigation System 


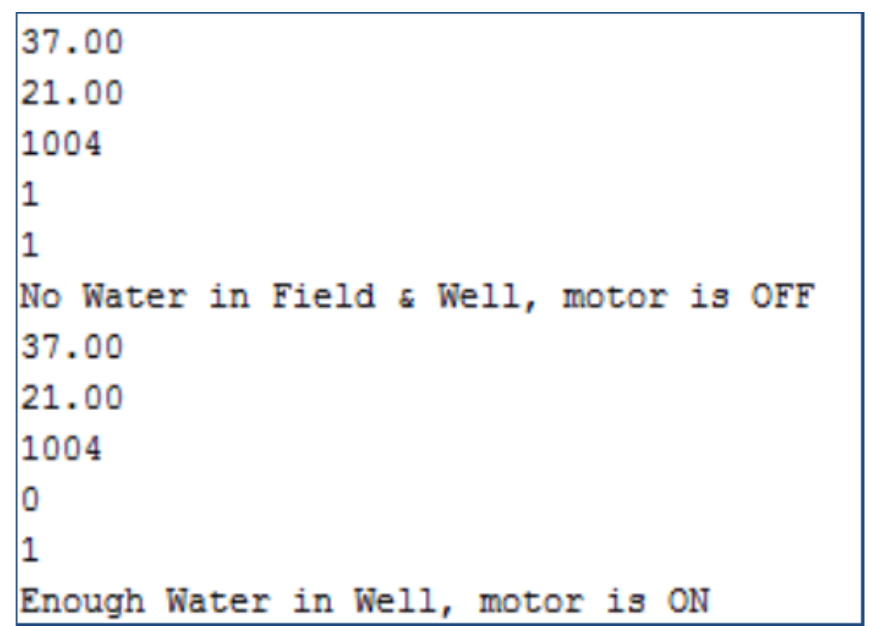

Figure 12 Experimental results on Arduino IDE Serial monitor

\section{Case 1:}

Figure 13 shows the various results from the field in PuTTY software window at the receiver section side. The temperature is $37^{\circ} \mathrm{C}$, humidity is $21 \%$, soil moisture ' 1004 '. This value indicates that soil is dry. The status of power ' 1 'indicates AC Power is available in the field. The status of motor is ' 0 ' indicates that motor is turned OFF. The water status indication ' 1 ' means there in no sufficient water in the well.

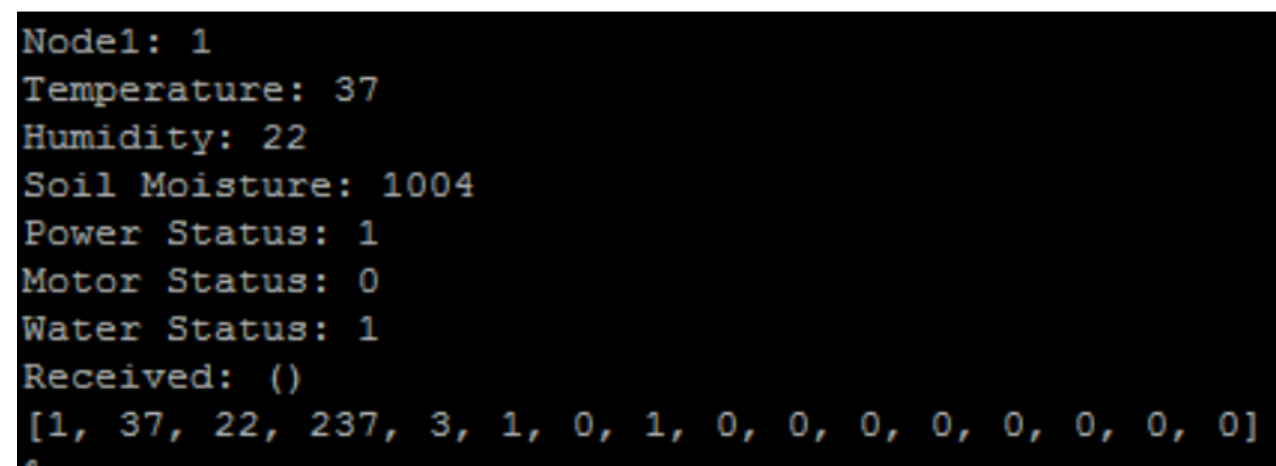

Figure 13 Experimental results displayed on PuTTY window at Receiver side for Case 1

Figure 14 shows the results of the various parameters and field status as uploaded on the Webpage for Case 1.

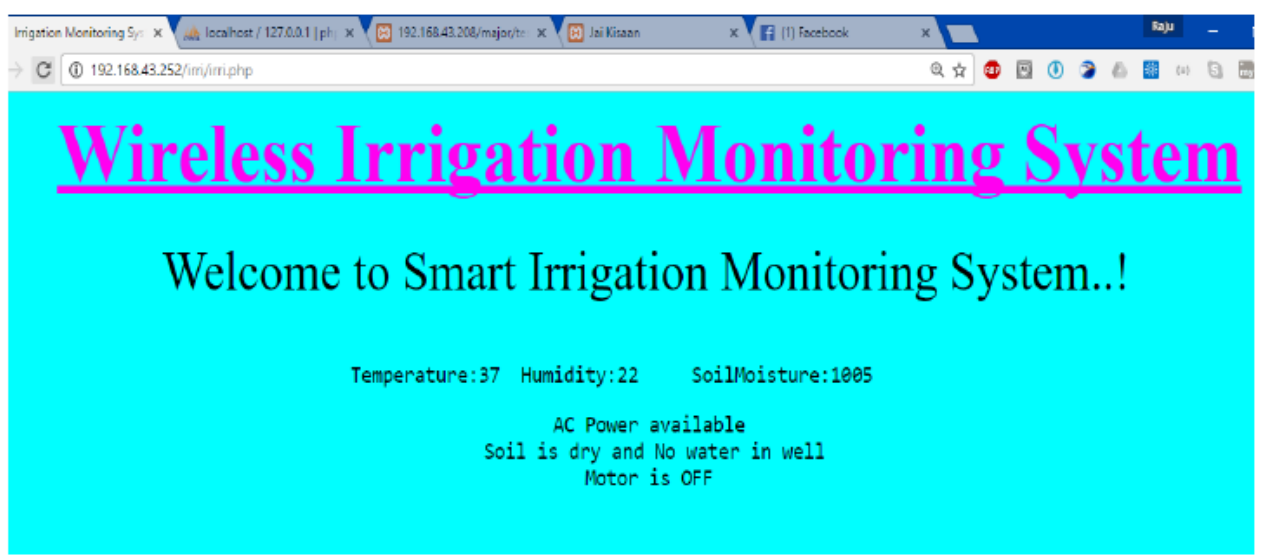

Figure 14 Webpage results of various parameters and status of field for Case 1 


\section{Case 2:}

Figure 15 shows another set of results from the field in PuTTY software window at the receiver section side. The temperature is $37^{\circ} \mathrm{C}$, humidity is $21 \%$, soil moisture ' 1004 '. This value indicates that soil is dry. The status of power ' 1 'indicates AC Power is available in the field. The status of motor is ' 1 ' indicates that motor is turned $\mathrm{ON}$. The water status indication ' 0 ' means there is sufficient water in the well.

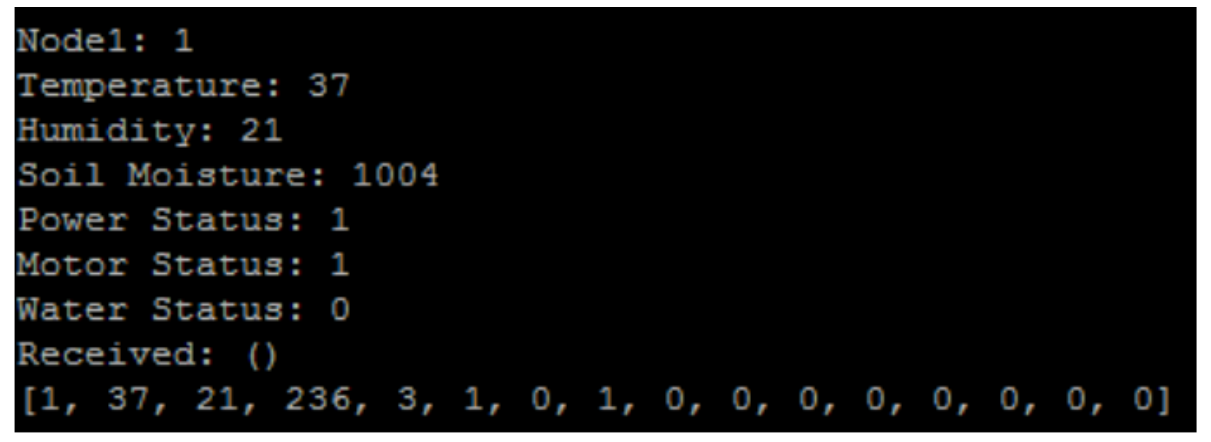

Figure 15 Experimental results displayed on PuTTY window at Receiver side for Case 2

Figure 16 shows the results of the various parameters and field status as uploaded on the Webpage for Case 2.

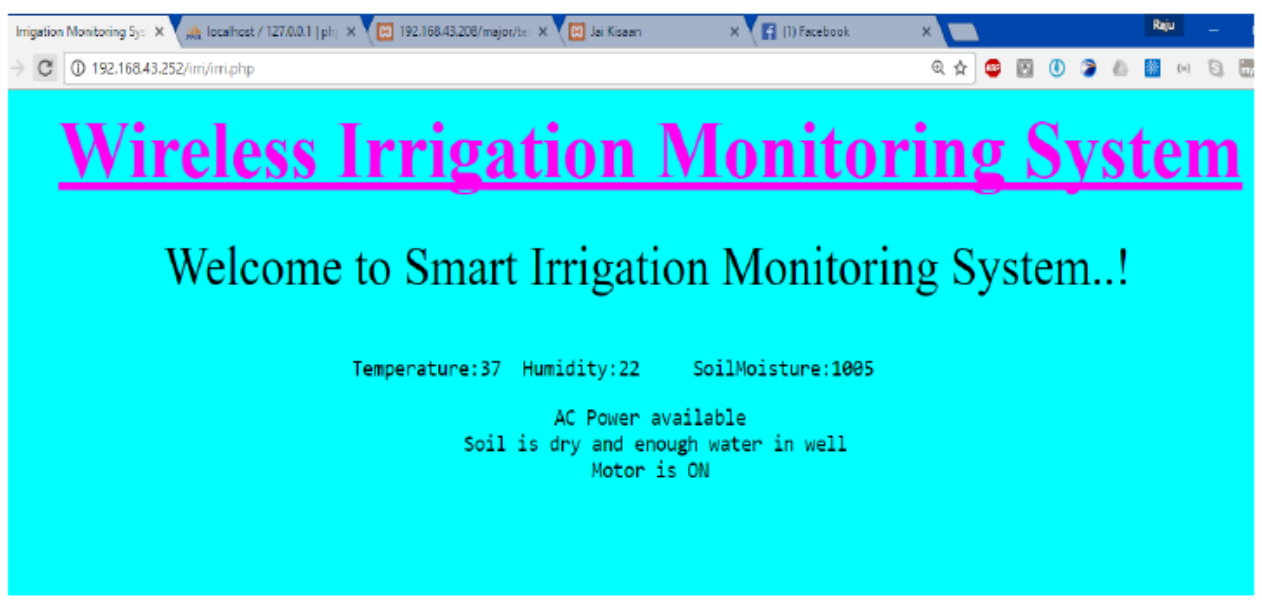

Figure 16 Webpage results of various parameters and status of field for Case 2

\section{CONCLUSIONS}

A prototype of Web based Smart Irrigation system is implemented using Arduino Uno and Raspberry Pi. A webpage is developed using HTML and PHP to display the status of various field parameters such as temperature, humidity and soil moisture and appropriate action taken so that farmer can know the status of the field by accessing the webpage. This system helps in reducing the wastage of water in the fields and avoids farmer going to field more number of times in a day.

\section{REFERENCES}

[1] Tanmay Baranwal, Nitika, and Pushpendra Kumar Pateriya "Development of IoT based smart security and Monitoring Devices for Agriculture", $6^{\text {th }}$ International Conference on Cloud System and Big Data Engineering, 14-15 Jan. 2016, Noida, India, pp.597-602, IEEE. 
[2] A. Sathya, B. Arthi, S. Giridharan, M. Karvendan, and J. Kishore, "Automatic control of irrigation system in paddy using WSN", IEEE Technological Innovations in ICT for Agriculture and Rural Development (TIAR), 15-16 July 2016, Chennai, India, pp. 115-118, IEEE.

[3] M. Usha Rani and S. Kamalesh "Web based service to monitor automatic irrigation system for the agriculture field using sensors", International Conference on Advances in Electrical Engineering (ICAEE), 9-11 Jan. 2014, Vellore, India, pp. 1-5, IEEE.

[4] Subhashree Ghosh, Sumaiya Sayyed, Kanchan Wani, Mrunal Mhatre, and Hyder Ali Hingoliwala, "Smart irrigation: A smart drip irrigation system using cloud, android and data mining", IEEE International Conference on Advances in Electronics, Communication and Computer Technology (ICAECCT), 2-3 Dec. 2016, pp.236-239, Pune, India.

[5] K.K. Namala, Krishna Kanth Prabhu A.V., Anushree Math, Ashwini Kumari, and Supraja Kulkarni, "Smart irrigation with embedded system", IEEE Bombay Section Symposium(IBSS), 21-22 Dec. 2016, Baramati, India, pp. 1-5, IEEE.

[6] https://www.raspberrypi.org/

[7] https://www.arduino.cc

[8] Nordic Semiconductor, "nRF24L01 Product specification, 2008.

[9] “DHT11 Humidity and Temperatue Digital Sensor", Datasheet, (https://www.microbot.it).

[10] https://en.wikipedia.org/wiki/PuTTY.

[11] Richard L. Halterman, “Learning to Program with Python”, 2011 (www.cs.uky.edu/).

[12] Larry Ullman, "PHP for the Web", Peachpit Press, San Francisco, 2016.

[13] Dr.Raju Anitha, S.Harsha Vardhan, Ch.Akhil and G.Sona, An Automated SMS-Update System through IOT using Raspberry Pi, International Journal of Mechanical Engineering and Technology 9(1), 2018, pp. 118-124

[14] Deepika Yadav, Yogendra Singh and Harshit Gupta, Controlling of Relay using Raspberry Pi Via Internet for Home Automation. International Journal of Advanced Research in Engineering and Technology, 9(1), 2018, pp 1-11.

[15] Anilkumar B and KRJ Srikanth, Design and Development of Real Time Paper Currency Recognition System of Demonetization New Indian Notes by Using Raspberry Pi for Visually Challenged, International Journal of Mechanical Engineering and Technology, 9(3), 2018, pp. 884-891.

[16] Trideep Singha Roy, Soumalya Ghosh, Rimpi Datta, Arpita Santra, IoT Based Home Automation Using Raspberry PI, International Journal of Computer Engineering and Technology 10(3), 2019, pp. 70-74. 